This item was submitted to Loughborough's Research Repository by the author.

Items in Figshare are protected by copyright, with all rights reserved, unless otherwise indicated.

\title{
Appraising the market for bicycle sharing schemes: Perceived service quality, satisfaction, and behavioural intention in London
}

PLEASE CITE THE PUBLISHED VERSION

https://doi.org/10.1016/j.cstp.2017.11.003

\section{PUBLISHER}

(c) World Conference on Transport Research Society. Published by Elsevier Ltd.

\section{VERSION}

AM (Accepted Manuscript)

\section{PUBLISHER STATEMENT}

This work is made available according to the conditions of the Creative Commons Attribution-NonCommercialNoDerivatives 4.0 International (CC BY-NC-ND 4.0) licence. Full details of this licence are available at: https://creativecommons.org/licenses/by-nc-nd/4.0/

\section{LICENCE}

CC BY-NC-ND 4.0

\section{REPOSITORY RECORD}

Morton, Craig. 2019. "Appraising the Market for Bicycle Sharing Schemes: Perceived Service Quality, Satisfaction, and Behavioural Intention in London". figshare. https://hdl.handle.net/2134/28302. 


\title{
Appraising the Market for Bicycle Sharing Schemes: Perceived service quality, satisfaction, and behavioural intention in London
}

\author{
Craig Morton \\ c.morton@live.co.uk \\ Transport Studies Group, School of Architecture, Building, and Civil Engineering, Loughborough \\ University, Leicestershire, LE11 3TU
}

\begin{abstract}
The implementation of bicycle sharing schemes represents an important innovation in urban public transport since the turn of the millennium. These schemes have spread rapidly and are now present in cities with varying economic, environmental, and structural conditions. Developing strategies through which to attract new members to join the scheme and retain existing members is a fundamental requirement for scheme success. The research reported in this paper provides guidance on this issue through a case study appraisal of the experiences that existing members have with the London Bicycle Sharing Scheme. This appraisal focuses on how the quality of service is perceived by members, their overall level of satisfaction with the scheme, their behavioural intentions toward renewing their memberships, and their willingness to recommend the scheme to others. A market segmentation analysis is produced which identifies the presence of four heterogeneous member groups. These member segments are profiled according to their demographic, psychographic, and behavioural characteristics. Through a detailed appreciation of the defining features of these member segments, strategies are proposed which are tailored to their specific needs and expectations.
\end{abstract}

\section{Keywords}

Bicycle sharing, quality of service, satisfaction, market segmentation

\section{Highlights}

- A market segmentation of the London bicycle sharing scheme identifies 4 distinct groups of members

- Each segment is defined by perceived quality of service, level of satisfaction, behavioural intention, and demographics

- The segment profiles are used to inform sub-market strategies to retain existing members and attract new members 


\section{Introduction}

The rate of global urbanisation is expanding rapidly as an increasing proportion of the population is born in or moves to cities. As a result of this, more attention is being paid to the design, operation, and management of urban transport systems in an effort to address the existing issues that the system faces (Banister, 2005; Goldman and Gorham, 2006). These issues include low levels of air quality, high levels of road congestion, and high levels of traffic noise, which mostly stem from the use of private motorised vehicles to service mobility needs.

Urban governments are in the process of developing strategies that aim to rebalance the transport system by diminishing the benefits of private motorised vehicles, restructuring urban forms to reduce car reliance, and enhancing the performance of public and active transport modes. One such strategy which has advanced rapidly since the millennium is the installation of bicycle sharing schemes (Fishman et al. 2013; Parkes et al. 2013), which have taken hold in cities with varying environmental and economic conditions. Such schemes provide flexible access to bicycles, with users generally being able to collect and return bicycles at stations located throughout the city for a set fee. These schemes respond to a number of prominent societal objectives including promoting a shift to active travel in urban environments, improving the health and wellbeing of citizens, and enhancing the urban realm by making cities more attractive places to live and do business. As such, the continued founding of new schemes and the expansion of existing schemes is viewed as an important element of urban transport policy. These objectives are in turn reliant on a detailed understanding of the consumer structure in this burgeoning market so that schemes can be tailored to best meet user needs and expectations.

To date, research on bicycle sharing schemes has focused on issues such as the factors that underpin user adoption (Shaheen et al. 2011; Fishman et al. 2015; Nikitas et al. 2016; Kim et al. 2017; Chardon et al. 2017) and the lessons learned from the operation of existing schemes (Shaheen et al. 2010; Ricci, 2015; Caulfield et al. 2017) in order to understand how schemes can be supported. This paper approaches the topic from a different direction, by investigating the experiences of existing scheme members through a case study of the London Bicycle Sharing Scheme (LBSS). A segmentation analysis is conducted in order to consider the consumer structure of this market and classifies members based on their perceived quality of service, satisfaction, usage patterns, behavioural intentions, cycling attitudes, and socioeconomic characteristics. As such, the analysis produces a rich description of consumer stratification, providing a source of market intelligence that can be used to develop urban transport policy such as sub-market strategy, which is tailored to the circumstances of targeted member segments.

This paper progresses by offering an overview of the LBSS, quality of service, how quality of service has been applied in transport studies, and the existing market segmentations of bicyclists. Following this, the methods section details the analytical procedure followed to conduct the market segmentation. The results of the segmentation are then described with a focus on the defining features of the identified segments. To conclude, the paper reflects on the importance of the results and makes a series of recommendations concerning how these findings can inform policy.

\section{Background}

\subsection{The London Bicycle Sharing Scheme}


Introduced in 2011, the LBSS represents a point-to-point short-term bicycle hire scheme, which allows user to collect bicycles from stations spread throughout central London and then subsequently return them to any station with a vacant docking bay. The LBSS can be accessed by anyone with a credit or debit card, with daily usage charged at $£ 2$ which provides unlimited journeys of up to 30 minutes (journeys longer than 30 minutes are charged at an additional $£ 2$ per 30 minutes). Users have the option to become members of the LBSS, with annual membership charged at $f 90$ which provides members with unlimited journeys of up to 30 minutes and a membership key that grants easy access to the bicycles. The LBSS underwent two stages of expansion, with the first stage extending the scheme eastward in 2012 while the second stage increased the reach of the scheme to the south-west in 2013. As of 2015, the LBSS had 11,500 bicycles available across 748 docking stations (Transport for London, 2015), with 240,000 active members and over 10 million annual bicycle hires in 2016 (Transport for London, 2016a). The continued expansion of the scheme is viewed as a central component of the Mayor's policy to transform London's transport system into one which is based on sustainable modes.

The LBSS has already attracted research attention, with empirical investigations covering an array of different issues. In an initial examination of LBSS member structure, Ogilvie and Goodman (2012) investigated the socio-demographic characteristics that are associated with frequency of scheme use and found that females and members that reside in areas with relatively high levels of deprivation tend to have lower usage levels. Female LBSS members are further evaluated by Beecham and Wood (2014) who analysed spatial usage patterns and found that females tend to prefer to use the scheme in areas with slower traffic and on streets that have cycle routes which are offset from major roads. The ability of LBSS to normalise the practice of cycling in city life was assessed by Goodman et al. (2014) though a comparison of LBSS users to other cyclists. LBSS users were found to be significantly less likely to wear specialist cycling apparel such as helmets, high-visibility clothes, and sports clothes. Goodman et al. (.ibid) concluded that the visibility of LBSS users in everyday attire demonstrates to the city population that cycling is not restricted to any particular social cohort (e.g. sporty people). The implications of extending of the LBSS to casual users (i.e. non-members) in late 2010 were examined by Lathia et al. (2012) in their spatial-temporal analysis of usage patterns which identified both global changes (i.e. a shift to increased scheme use at weekends) and local changes (i.e. certain stations undergoing substantial changes in their trip patterns) in scheme use.

\subsection{Quality of Service}

The swift expansion of the service sector throughout much of the economically developed world from the mid-twentieth century motivated research into the issues that are influential in the experience that service customers receive (Berry et al. 1985). The focus of the research was often on how service is perceived by customers, investigating subjective issues (e.g. the demeanour of service personnel) rather than objective facts (e.g. the scheduled reliability of a train service). Through such investigations, strategies can be developed by service providers to improve service provision in order to expand their market and compete with rival providers.

A series of instruments were developed to monitor perceived quality of service across a set of standard dimensions which are likely to be present in most service settings. SERVQUAL represents one of the most frequently applied instruments (Parasuraman et al. 1985; Parasuraman et al. 1988; Parasuraman et al. 1991), which covers a multi-item measurement scale including the dimensions of tangibles (e.g. physical features such as seats), reliability (e.g. the service operating in a consistent fashion), assurance (e.g. the expertise of drivers), responsiveness (e.g. the timeliness of service personnel), and 
empathy (e.g. the establishment of a relationship between the customer and service personnel). These different dimensions were considered by evaluating the gap between what customers expect a service provider to deliver and the perceived performance of the service provider. If expectations are met, customers are classified as being satisfied whereas if performance falls below expectations, customers are classified as dissatisfied. Through this assessment, service providers are able to identify areas where provision needs to be improved in order to enhance satisfaction.

One apparent limitation of the SERVQUAL approach is the need to take two measurements of each item (i.e. a measurement of expectation and perceived performance), which can make the application of the instrument somewhat cumbersome. To address this issue, Cronin and Taylor (1992) developed the SERVPERF measurement scale, which directly asks customers to express their perceptions of the service quality dimensions. Thus, SERVPERF represents a more concise approach and allows the scale to be evaluated using conventional techniques such as factor analysis. In addition, SERVPREF allows for conceptual extension through the inclusion of such issues as satisfaction, retention, and recommendation to provide a more complete assessment of customer experience (Cronin and Taylor, 1994; Taylor and Baker, 1994; Cronin et al. 2000).

\subsection{Transport Sector Quality of Service Applications}

The provision of mobility services in the transport sector represents a common site of application for quality of service assessments. These can generally originate from two sources. First, transport operators (e.g. bus companies and airlines) can appraise their services in order to identify areas which require attention. Second, authorities tasked with regulating the provision of public transport services can utilise quality of service assessments as part of their performance monitoring of operators. Such assessments can underpin service contracts, making them a crucial element in the negotiation which occurs between authorities and operators.

Quality of service assessments are present across all of the traditional modes of public transport including bus (Eboli and Mazzulla, 2007; Stradling et al. 2007; Yaya et al. 2014; Mahmoud and Hine, 2016; Morton et al. 2016; Grisé and El-Geneidy, 2017), rail (Nathanail, 2008; Chou et al. 2014; Eboli and Mazzulla, 2015; Yanik et al. 2017), and airline (Fick and Ritchie, 1991; Ostrowski et al. 1993; Pakdil and Aydin, 2007) operations. A comprehensive review of the literature in this area is offered by Lierop et al. (2017), who investigated the dimensions that have commonly been found to effect the level of satisfaction experienced by public transport passengers and the intention to continue using the service. Their review indicates that particularly important issues for satisfaction are on-board cleanliness, comfort, and the courteousness of service personnel. A somewhat different set of factors is found to effect customer retention, with value-for-money, on-board safety, and the image of public transport being prominent dimensions.

To date, applications of quality of service investigations for bicycle sharing schemes have been scarce, likely due to how recently this service has come to prominence. One early investigation was conducted by Zhang et al. (2015), who examined the connection between quality of service, satisfaction, and usage frequency in the bicycle sharing scheme in Hangzhou, China. Through the application of a thirty item measurement scale, their analysis indicates that satisfaction levels are associated with such issues as the level of illumination on routes, the procedure through which the initial deposit for scheme membership is returned, the handling of complaints by service personnel, and the distribution of stations. In turn, the overall level of satisfaction holds a positive effect on the frequency of use having controlled for the effect of demographic characteristics. A somewhat different set of findings 
were observed in a recent study of the bicycle sharing scheme in Milan, Italy (Manzi and Saibene, 2017), where users tend to state high levels of overall satisfaction with the scheme, but remain critical of the mechanisms associated with scheme operation such as the quality of the bicycles and the procedures for collecting and returning bicycles.

The combination of the rapid expansion of bicycle sharing schemes and the relative scarcity in evaluations of user satisfaction with these schemes indicates a need for further research in this area. The analysis presented in this paper responds to this need by assessing the issues that underpin member satisfaction with the LBSS through an evaluation of the quality of a service indicator applied by Transport for London.

\subsection{Market Segmentation}

Generally, research investigating the perceived quality of public transport services has approached the issues from a market-level perspective. That is to say, the focus has primarily been on the generalisations which tend to hold for all users, often through the application of regression modelling and structural equation modelling. One approach that has received less attention concerns customer heterogeneity, which distinguishes users based on their characteristics and needs (Smith, 1956). This approach is often referred to as market segmentation, which investigates the presence of groups of users that share similarities with one another. Understanding the structure of the consumer groups that are present within a market allows for the development of sub-market strategies which are tailored towards the features, needs, and expectations of particular segments (Lin, 2002; Savan et al. 2017).

The combination of market segmentation with quality of service appraisal has the potential to offer insights regarding the expectations of different consumer groups (Webb, 1998) and in promoting switching behaviour (Athanassopoulos, 2000). Webster (1989) illustrated these points in an initial investigation which examined how the SERVQUAL quality of service dimensions differentiate across demographic cohorts for both professional (e.g. medical and legal) and non-professional (e.g. automotive and cleaning) services. The findings of this investigation indicate that quality of service expectations are distinct across cohorts for professional services, but not for non-professional services, with expectations tending to be greater for females, older individuals, married customers, and higher income customers. Application of market segmentation through quality of service in the transport sector have to date been small in number and primarily limited to bus services (SánchezPérez, 2007; Oña and Oña, 2013; Oña et al. 2014), through the results of these cases indicate that considerable differences in perceptions can be identified across user groups.

With past research having identified significant levels of heterogeneity in cyclists at a general level (Dill and McNeil, 2012; Damant-Sirois et al. 2014; Damant-Siros and El-Geneidy 2015), the research present in this paper investigates whether stratification exists amongst members of a bicycle sharing scheme specifically and, if this is indeed the case, what insights this knowledge has for scheme operation.

\section{Methods}

\subsection{Data Source and Preparation}


Since 2013, Transport for London (the local transport authority) has deployed an annual survey amongst members of the LBSS to monitor experiences with the scheme. This survey is conducted online and invites members to participate if they have used the scheme in the previous three months. The research reported in this paper makes use of the 2016 dataset generated by this survey (Transport for London, 2016b), which was distributed to 29,970 active members with 2,935 completed surveys received, representing a response rate of $9.8 \%$. The survey allowed members to decline to answer questions (such as household income), leading to only partial observations for certain respondents. Due to this, the analysis is based on a trimmed version of the survey which removes respondents that declined to provide answers to variables included in the analysis. As such, the sample size for the analysis is 1,476 . Descriptive statistics of the socioeconomic characteristics of the sample are presented in Table 1.

Table 1: Descriptive Statistics of the socioeconomic characteristics of London Bicycle Sharing Scheme members $(n=1,476)$

\begin{tabular}{|c|c|c|}
\hline Variable & Category & Sample \\
\hline \multirow[t]{6}{*}{ Age } & $16-24$ & $3.5 \%$ \\
\hline & $25-34$ & $27.6 \%$ \\
\hline & $35-44$ & $29.6 \%$ \\
\hline & $45-54$ & $24.9 \%$ \\
\hline & $55-64$ & $12.5 \%$ \\
\hline & $65+$ & $1.9 \%$ \\
\hline \multirow[t]{2}{*}{ Gender } & Female & $21.8 \%$ \\
\hline & Male & $78.2 \%$ \\
\hline \multirow[t]{7}{*}{ Economic Status } & Employed Full-time & $87.8 \%$ \\
\hline & Employed Part-time & $6.4 \%$ \\
\hline & Looking after Home & $0.2 \%$ \\
\hline & Retired & $2.0 \%$ \\
\hline & Unemployed & $1.2 \%$ \\
\hline & Student & $1.9 \%$ \\
\hline & Other & $0.5 \%$ \\
\hline \multirow[t]{7}{*}{ Household Income } & Less than $f 10,000$ & $2.8 \%$ \\
\hline & £10-14,999 & $1.5 \%$ \\
\hline & £15-19,999 & $2.4 \%$ \\
\hline & f20-29,999 & $7.1 \%$ \\
\hline & £30-39-999 & $11.5 \%$ \\
\hline & $£ 40-75,000$ & $28.5 \%$ \\
\hline & Over $£ 75,000$ & $46.3 \%$ \\
\hline \multirow[t]{5}{*}{ Ethnicity } & White & $92.5 \%$ \\
\hline & Mixed & $2.7 \%$ \\
\hline & Asian & $2.2 \%$ \\
\hline & Black & $0.6 \%$ \\
\hline & Other & $2.0 \%$ \\
\hline \multirow[t]{3}{*}{ Residence } & Rest of UK & $8.3 \%$ \\
\hline & South East England & $19.9 \%$ \\
\hline & London & $71.9 \%$ \\
\hline
\end{tabular}




\subsection{Quality of Service Indicator}

Embedded in the survey is a ten item quality of service indicator utilised by Transport for London to evaluate perceptions of the LBSS. This indicator covers such issues as availability of bicycles and docking points, the information provided at the station terminals, and the perceived value for money of the scheme. In addition, the survey measures the attitudes that members hold towards cycling in general and the LBSS through a series of opinion statements. These items and statements are summarised in Table 2 which reports summary statistics and the label assigned to the item or statement.

Table 2: Descriptive statistics of (a) the quality of service indicator and (b) attitudes towards cycling and the LBSS

\begin{tabular}{|c|c|c|c|c|}
\hline Label & Statement & Mean & S.D. & Skew \\
\hline \multicolumn{5}{|c|}{ Quality of Service and Satisfaction (1: Extremely Dissatisfied to 11: Extremely Satisfied) * } \\
\hline Overall & Your overall experience of the London Cycle Sharing Scheme & 7.61 & 16.08 & -1.48 \\
\hline Info & The information on how the London Cycle Sharing Scheme works & 7.66 & 16.74 & -1.25 \\
\hline A: Bikes & The availability of bicycles at docking stations & 6.46 & 21.33 & -0.81 \\
\hline A: Points & $\begin{array}{l}\text { The availability of free docking points to return bicycles at } \\
\text { stations }\end{array}$ & 5.90 & 22.72 & -0.56 \\
\hline Stations & $\begin{array}{l}\text { The working condition and general maintenance of the docking } \\
\text { stations }\end{array}$ & 7.88 & 15.20 & -1.34 \\
\hline Key & The ease of using the membership key to access a bicycle & 8.77 & 17.33 & -2.54 \\
\hline Terminals & $\begin{array}{l}\text { The information panels, print outs, screens and ease of using the } \\
\text { terminals }\end{array}$ & 7.17 & 20.47 & -0.10 \\
\hline Maps & The maps at the terminals & 7.61 & 20.64 & -1.19 \\
\hline Bikes & The bicycles you have hired & 7.44 & 15.23 & -1.02 \\
\hline VFM & The value for money of the London Cycle Sharing Scheme & 7.20 & 22.32 & -0.93 \\
\hline \multicolumn{5}{|c|}{ Attitudes towards Cycling and the LBSS (1: Highly Disagree to 11: Highly Agree) ** } \\
\hline Enjoy & Cycling is enjoyable & 9.60 & 1.63 & -1.69 \\
\hline Safe & Cycling is a safe way of getting about & 6.34 & 2.43 & -0.36 \\
\hline Rush & Cycling is good for rush hour journeys & 8.39 & 2.49 & -1.15 \\
\hline Facility & There are good facilities for cyclists in London & 6.50 & 2.41 & -0.48 \\
\hline $\begin{array}{l}\text { LBSS: } \\
\text { Positive }\end{array}$ & $\begin{array}{l}\text { The London Cycle Sharing Scheme makes a positive contribution } \\
\text { to London }\end{array}$ & 9.60 & 1.55 & -1.54 \\
\hline $\begin{array}{l}\text { LBSS: } \\
\text { Safe }\end{array}$ & $\begin{array}{l}\text { The London Cycle Sharing Scheme has helped to make cycling in } \\
\text { London safer }\end{array}$ & 7.15 & 2.45 & -0.46 \\
\hline
\end{tabular}

\subsection{Statistical Approach}

The market segmentation analysis follows a multi-stage procedure in order to partition the sample into groups of members and is based on the market appraisal guidance outlined by Mooi and Sarsted (2011). This relies primarily on the application of cluster analysis to identify member groups that share similarities in their characteristics and is different to an a-prior segmentation that partitions members based on a pre-defined criteria (e.g. delineating members based on gender or primary trip purpose). 
Stage one involves the selection of an appropriate batch of segmentation variables which are used to consider the similarities and differences that exist between LBSS members. As this research is primarily interested in understanding the experiences of LBSS members, the items associated with the quality of service indicator reported in Table 2 are utilised as the segmentation variables. Stage two employs a Hierarchical cluster analysis following a Ward's method with squared Euclidean distance (Everitt et al. 2009) in order to consider the manner in which the sample is partitioning and produce an initial solution. Stage three covers the selection of the appropriate number of segments to base the final solution on and follows two steps. The first step relates to how technically optimal the solution is at identifying segments which are internally homogenous (i.e. the members of a segment are alike) and externally heterogeneous (i.e. the segments are unique from one another). This is pursued through the calculation of the Variance Inflation Criterion (Caliński and Harabasz, 1974). The second step covers a critical evaluation of the usefulness of the alternative solutions. Stage four takes the centroids from the initial Hierarchical analysis and uses them as seed points for a K-Means cluster analysis (Hartigan and Wong, 1979) to produce the final solution. Stage five considers the differences that exist between the identified market segments based on their loadings across five groups of descriptive variables covering the quality of service indicator, usage frequencies, behavioural intentions, cycling attitudes, and socioeconomic characteristics. Due to the high number of tests of difference (a mixture of chi-square and Kruskal Wallis tests) made between the identified segments across the descriptive variables, the Bonferroni correction is applied to mitigate Type 1 error (i.e. false positives). These analysis stages are summarised in Figure 1.

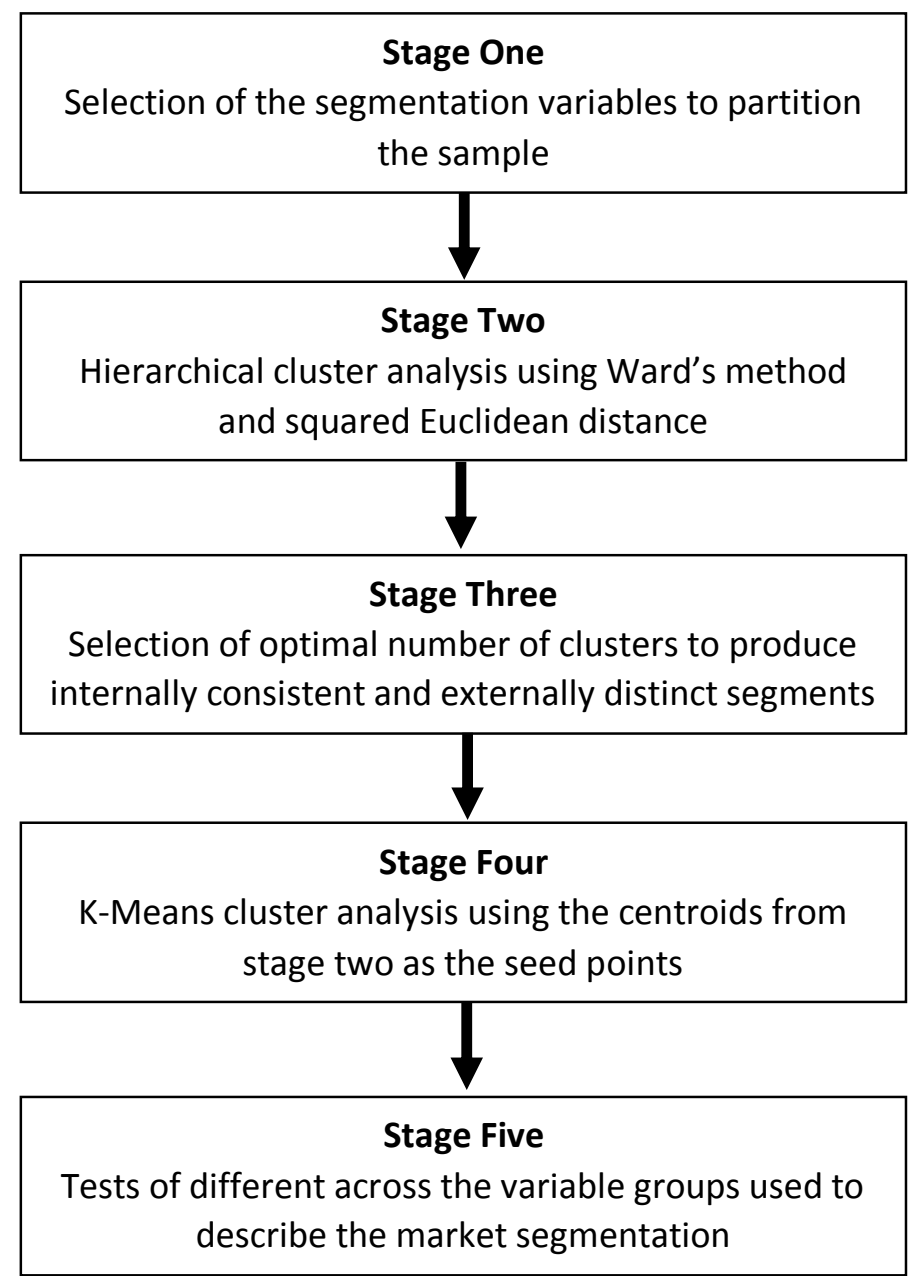

Figure 1: Summary of the multi-stage market segmentation analysis 


\subsection{Limitations}

The analysis reported in this paper is based on a public record survey which was developed by Transport for London to service their data needs (i.e. the survey is used as secondary data in this analysis). As a consequence of this, the structure of the survey was not designed with reference to a pre-existing theory of service quality (e.g. SERVQUAL or SERVPERF). Thus, the analysis cannot test the appropriateness of conventional quality of service dimensions (e.g. responsiveness and assurances) embedded in the existing conceptual frameworks of user satisfaction, as these dimensions were not measured by the survey. Due to this, the analysis is limited to examining the dimensions selected by Transport for London, meaning the analysis is more focused on the issues that are practically relevant to Transport for London's management of the system rather than being orientated around a theoretical structure of service quality. Moreover, the sampling method followed by Transport for London to collect the data cannot assess the degree to which the sample captured accurately represents the population of members, as no population statistics are available. As such, how accurately the member segments identified in the analysis match those inherent in the population cannot be evaluated.

\section{Results}

The segmentation analysis identified the presence of four groups of members, with these segments displaying high levels of internal consistency and external distinction. This number of segments also proves to be appropriate for the development of market strategy, as it allows for a manageable set of comparisons to occur and proposals to be put forward. Each of the identified segments is described in terms of how they load onto a set of descriptive characteristics which cover perceptions of service quality and satisfaction, usage patterns, behavioural intentions, cycling attitudes, and demographics. In an effort to aid the interpretation of the findings, each segment has been assigned a name and their core features have been summarised with these details presented in Figure 2. Two relatively large segments are identified, covering the Satisfied Commuters and Keen Renewers, with two relatively small segments in the Low Frequenters and Dissatisfied Out-of-Towners. 


\section{Segment 1 - Satisfied Commuters Segment 2-Keen Renewers}

Label - SC; Size-31\%

- High score on the quality of service indicator, though low on availability of bicycles and return points

- Use the LBSS frequently for commuting

- Increased tendency to think that the availability of bicycles and return stations has gotten worse

- Likely to renew membership

- Positive attitude towards cycling and the LBSS

\section{Segment 3 - Low Frequenters}

Label - LF; Size $-22 \%$

- Moderate score on the quality of service indicator, though distinctly low on perceived value for money

- Lowest usage frequency of the LBSS

- Moderately high level of considering the LBSS to have improved

- Low level of failure to find available bicycles, return points, and to complete journeys

- Moderately high reluctance to recommend the LBSS
Label KR; Size - 33\%

- Highest score on the quality of service indicator, particularly on the maintenance of the stations and the membership key used to access bicycles

- Consider the availability of bicycles and return points to have improved

- Low level of failures to complete a journey in the past 6 months

- Highest level of willingness to recommend the LBSS and to renew membership

- Relatively high level of residence outside of London

Segment 4- Dissatisfied Out-of-Towners Label - DT; Size - 14\%

- Lowest score on the quality of service indicator, especially concerning the availability of bicycles and return stations

- Highest use frequency of the LBSS for commuting and professional business

- High rating on perceptions that the LBSS has gotten worse

- Highest rate of failure to find available bicycles, return points, and to complete journeys

- Low level of willingness to recommend the LBSS

- Highest rate of South-East of England residents

Figure 2: Summarised descriptions of the four member segments of the London Bicycle Sharing Scheme

The manner in which the segments load on overall level of satisfaction with the LBSS is summarised in Figure 3 and indicates that the Low Frequenters, Keen Renewers, and Satisfied Commuters generally have high levels of satisfaction with the operation of the scheme, with mean loadings of between 8 and 10 and relatively low levels of dispersion. Conversely, Dissatisfied Out-of-Towners display relatively negative levels of satisfaction with the LBSS, with a mean loading of 6.36 and a distinct negative skew to the data. 


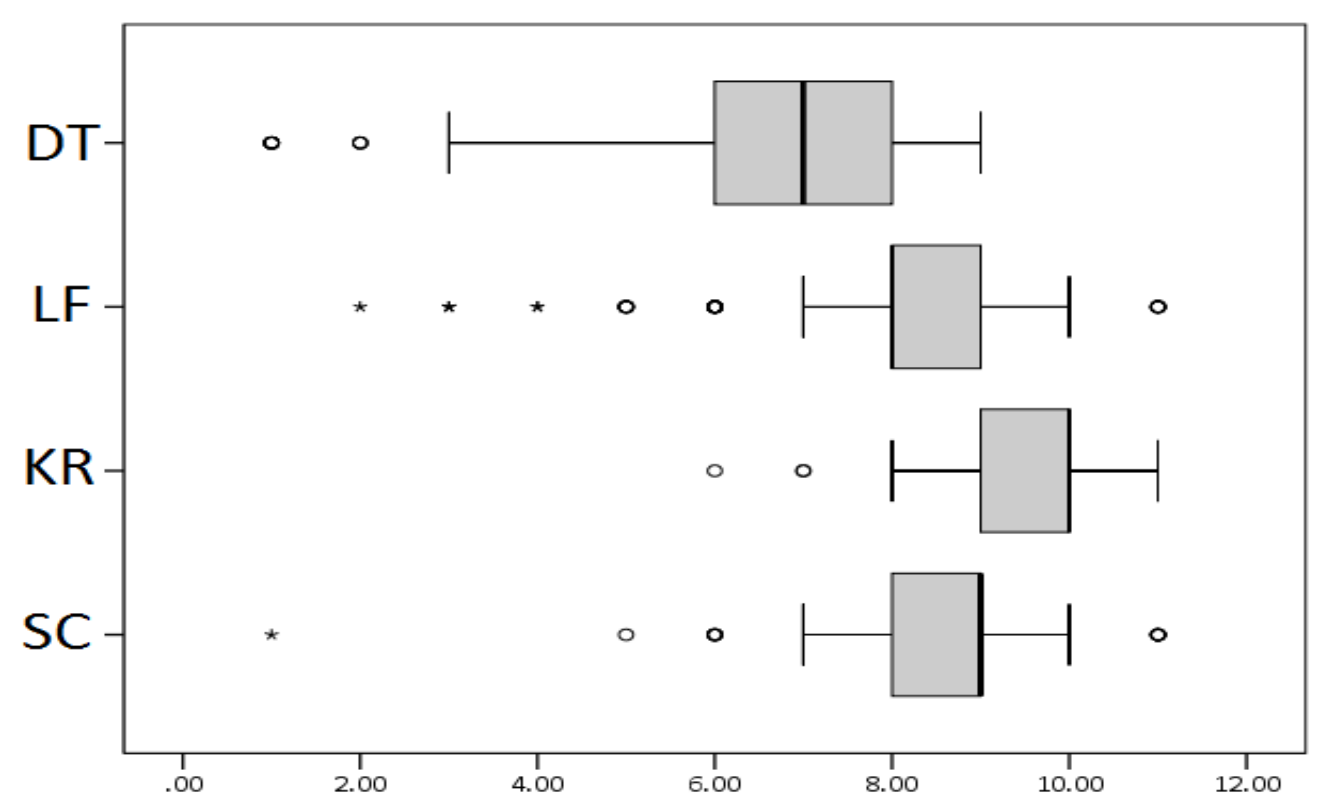

Figure 3: Boxplot of member segments on the item measuring overall satisfaction with the LBSS (Overall) - Kruskal Wallis test $\mathrm{H}=670.293, \mathrm{p}<.001$

The segment loadings on the perceived quality of service indicator items are reported in Figure 4, with each of these items described in Table 2. The results indicate that Dissatisfied Out-of-Towners hold relatively negative evaluations of the LBSS quality dimensions, particularly concerning the availability of bicycles (A: Bicycles) and points to return bicycles to (A: Points). Conversely, Keen Renewers tend to display positive appraisals of the LBSS across all items, with a notably high loading on perceived quality with the maps available at stations (Maps) and the stations generally (Stations). Interestingly, Low Frequenters, who tend to display moderate evaluations of quality of service and satisfaction, have a distinctly negative loading on the item measuring perceived value for money of the LBSS (VFM). This may imply that Low Frequenters are particularly price sensitive. 

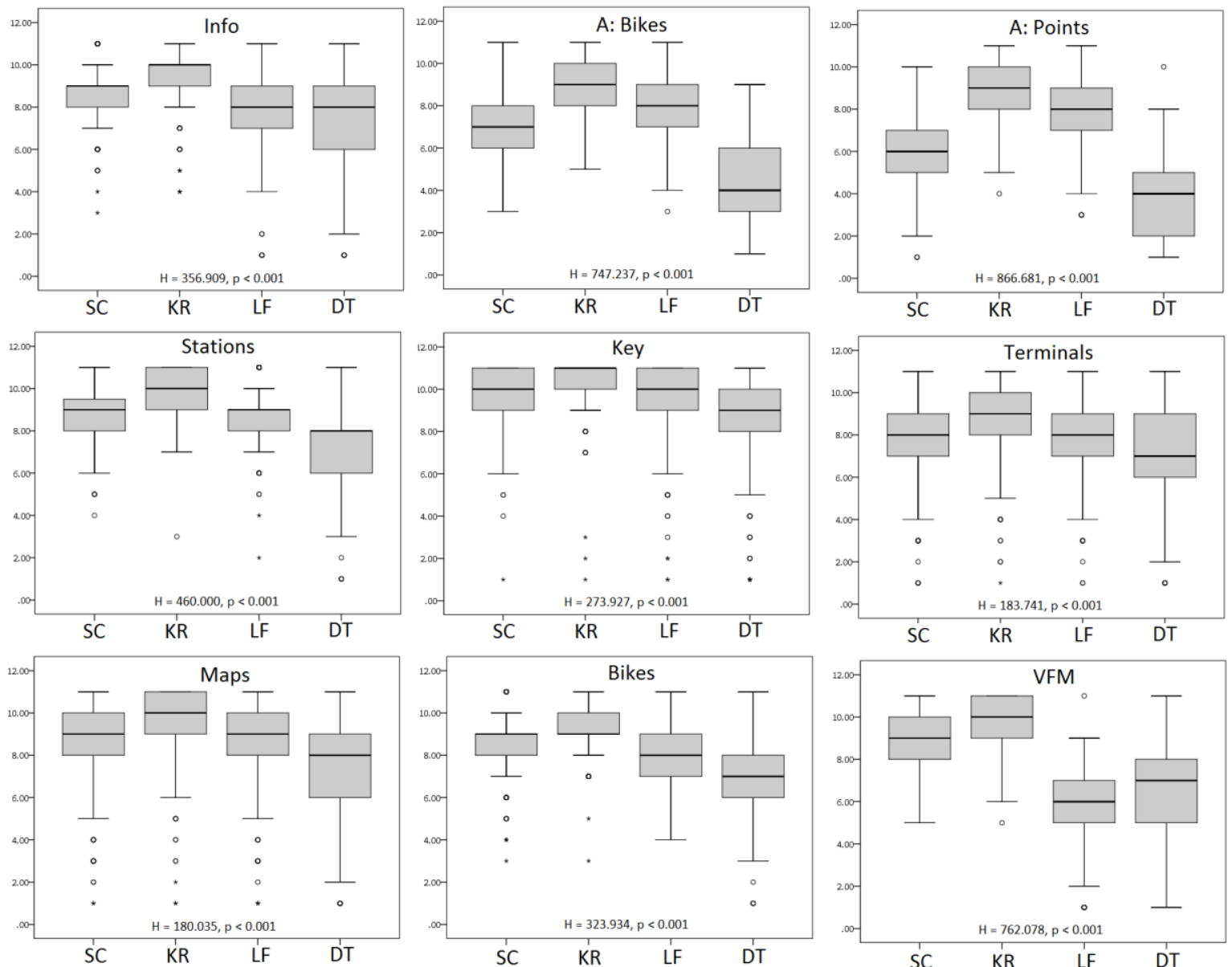

Figure 4: Boxplots of the member segments on the quality of service indicator items outlined in Table 2

The usage frequencies by trip purpose are reported in Figure 5, providing insights regarding how often and for what reason the member segments use the LBSS. Two significant differences are observed between the member segments. First, Satisfied Commuters and Dissatisfied Out-of-Towners tend to use the LBSS more frequently for commuting, with Low Frequenters having relatively low levels of use for this purpose. Secondly, Dissatisfied Out-of-Towners display relatively high frequencies of use for professional business (i.e. in the course of employment). For other trip purposes recorded in the survey (i.e. education, leisure, personal business, shopping, socialising, and visiting friends and family), no significant differences between the member segments are present. This may indicate that high levels of user group heterogeneity across usage patterns are not present. 


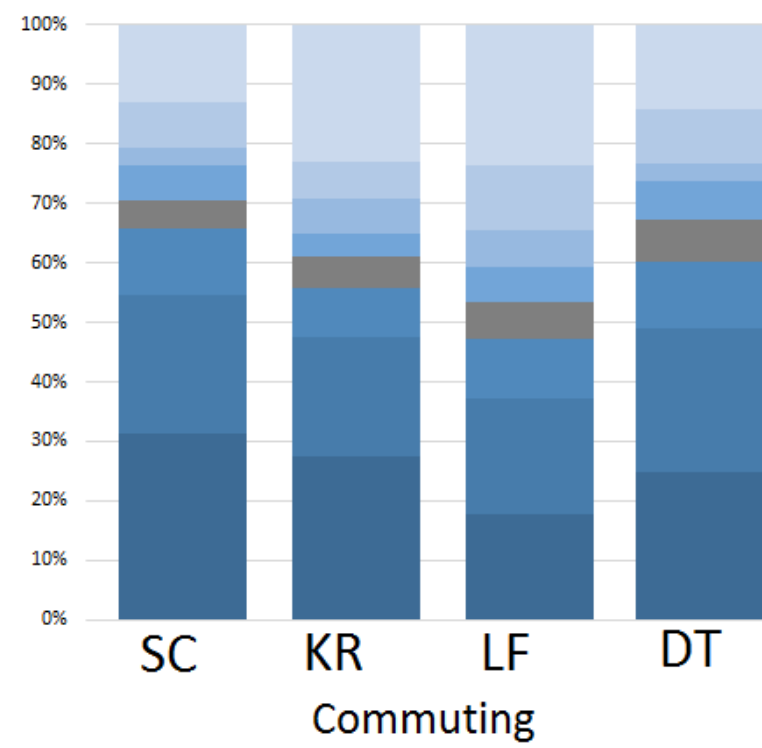

$X^{2}=58.579, p<0.01$

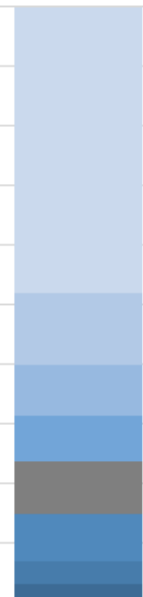

SC KR

Professional Business

$X^{2}=56.973, p<0.01$

5+ days a week - 3-4 days a week $\square 2$ days a week $\square$ Once a week Once a fortnight $\square$ Once a month $\square$ Less than once a month Never

Figure 5: Usage frequencies for (a) Commuting and (b) Professional Business of the member segments

Table 3 summarises how the member segments load on a series of variables that measure their experiences with the scheme as well as behavioural intentions towards the scheme. The results of the analysis indicate that Dissatisfied Out-of-Towners are more likely to perceive that the operation of the LBSS has gotten worse in reference to the use of the membership key to access bicycles as well as the availability of bicycles and return points. Conversely, Keen Renewers have a higher likelihood of considering that the availability of bicycles and return points has improved. Both Satisfied Commuters and Dissatisfied Out-of-Towners comprise a higher proportion of members that have failed to locate a bicycle or a return point in the month prior to the survey, with Dissatisfied Out-of-Towners also having an increased likelihood of not being able to complete an intended journey in the past 6 months. These experiences appear to be translating into the willingness of members to recommend the LBSS, with Dissatisfied Out-of-Towners being significantly less likely to recommend whereas Keen Renewers display a much higher readiness to recommend. Interestingly, whilst Dissatisfied Out-of-Towners are more likely to terminate their memberships as compared to the other segments, still over $80 \%$ intend to renew, suggesting that the negative experiences of this segment with the LBSS are not transferring into a particularly high level of withdrawal. Additionally, Low Frequenters represents members that are undecided whether or not to recommend the LBSS, perhaps due to their relatively negative perceptions of the value for money of the scheme. 
Table 3: The experiences and behavioural intentions of the member segments

\begin{tabular}{|c|c|c|c|c|c|}
\hline \multirow{2}{*}{ Variable } & \multirow{2}{*}{ Category } & SC & KR & LF & DT \\
\hline & & $(n=459)$ & $(n=484)$ & $(n=320)$ & $(n=213)$ \\
\hline \multirow{3}{*}{$\begin{array}{l}\text { Membership key } \\
x^{2}=35.193, p<.001\end{array}$} & Improved & $20.8 \%$ & $20.5 \%$ & $23.2 \%$ & $15.0 \%$ \\
\hline & Stayed the same & $76.8 \%$ & $77.0 \%$ & $72.8 \%$ & $74.3 \%$ \\
\hline & Got worse & $2.4 \%$ & $2.5 \%$ & $4.0 \%$ & $10.7 \%$ \\
\hline \multirow{3}{*}{$\begin{array}{l}\text { Availability of bicycles } \\
x^{2}=241.994, p<.001\end{array}$} & Improved & $26.9 \%$ & $43.8 \%$ & $35.3 \%$ & $8.9 \%$ \\
\hline & Stayed the same & $58.4 \%$ & $53.5 \%$ & $58.8 \%$ & $51.4 \%$ \\
\hline & Got worse & $14.7 \%$ & $2.7 \%$ & $5.9 \%$ & $39.7 \%$ \\
\hline \multirow{3}{*}{$\begin{array}{l}\text { Availability of docking } \\
\text { points } \\
x^{2}=217.820, p<.001\end{array}$} & Improved & $18.4 \%$ & $35.7 \%$ & $28.5 \%$ & $7.0 \%$ \\
\hline & Stayed the same & $60.4 \%$ & $58.9 \%$ & $61.6 \%$ & $48.1 \%$ \\
\hline & Got worse & $21.2 \%$ & $5.4 \%$ & $9.9 \%$ & $44.9 \%$ \\
\hline Failed to find an available & Yes & $80.7 \%$ & $61.2 \%$ & $61.3 \%$ & $82.7 \%$ \\
\hline $\begin{array}{l}\text { bicycle in last month } \\
x^{2}=71.944, p<.001\end{array}$ & No & $19.3 \%$ & $38.8 \%$ & $38.7 \%$ & $17.3 \%$ \\
\hline Failed to find a return & Yes & $85.6 \%$ & $64.1 \%$ & $62.2 \%$ & $84.6 \%$ \\
\hline $\begin{array}{l}\text { station in last month } \\
x^{2}=90.855, p<.001\end{array}$ & No & $14.4 \%$ & $35.9 \%$ & $37.8 \%$ & $15.4 \%$ \\
\hline Problem preventing & Yes & $38.6 \%$ & $24.4 \%$ & $29.7 \%$ & $41.2 \%$ \\
\hline $\begin{array}{l}\text { completing journey in last } \\
6 \text { months } \\
x^{2}=32.476, p<.001\end{array}$ & No & $61.4 \%$ & $75.6 \%$ & $70.3 \%$ & $58.8 \%$ \\
\hline \multirow{6}{*}{$\begin{array}{l}\text { Year of registration } \\
\chi^{2}=15.945, p=.386\end{array}$} & 2010 & $26.9 \%$ & $29.9 \%$ & $30.0 \%$ & $28.5 \%$ \\
\hline & 2011 & $11.4 \%$ & $9.1 \%$ & $14.6 \%$ & $9.3 \%$ \\
\hline & 2012 & $10.7 \%$ & $11.0 \%$ & $13.6 \%$ & $11.7 \%$ \\
\hline & 2013 & $7.4 \%$ & $5.8 \%$ & $4.3 \%$ & $6.5 \%$ \\
\hline & 2014 & $26.9 \%$ & $27.6 \%$ & $25.1 \%$ & $25.2 \%$ \\
\hline & 2015 & $16.6 \%$ & $16.6 \%$ & $12.4 \%$ & $18.7 \%$ \\
\hline \multirow[t]{3}{*}{$\begin{array}{l}\text { Recommendation } \\
x^{2}=442.453, p=<.001\end{array}$} & $\begin{array}{l}\text { Would } \\
\text { recommend }\end{array}$ & $86.9 \%$ & $96.9 \%$ & $67.5 \%$ & $32.7 \%$ \\
\hline & Neutral & $12.7 \%$ & $2.7 \%$ & $29.7 \%$ & $50.5 \%$ \\
\hline & $\begin{array}{l}\text { Would not } \\
\text { recommend }\end{array}$ & $0.4 \%$ & $0.4 \%$ & $2.8 \%$ & $16.8 \%$ \\
\hline \multirow{3}{*}{$\begin{array}{l}\text { Renewal } \\
x^{2}=26.595, p=<.001\end{array}$} & Yes & $89.5 \%$ & $91.3 \%$ & $84.0 \%$ & $80.6 \%$ \\
\hline & No & $3.7 \%$ & $2.9 \%$ & $5.3 \%$ & $10.6 \%$ \\
\hline & Auto renew & $6.7 \%$ & $5.8 \%$ & $10.6 \%$ & $8.9 \%$ \\
\hline
\end{tabular}

The attitudes that the member segments hold towards cycling and the LBSS are displayed in Figure 6 with each of these items described in Table 2. The patterning of the segment loadings is markedly consistent, with the same rank order of the segments on each opinion statement (in terms of mean loadings). There is a partial overlap apparent concerning the segment loadings on these attitudes and their loadings on the quality of service items. For instance, Keen Renewers tend to have relatively positive evaluations of the LBSS in terms of quality and overall satisfaction whilst holding relatively positive attitudes towards cycling and the LBSS. This situation is reversed for Dissatisfied Out-ofTowners, who tend to have negative evaluations and attitudes on these issues. This partial overlap 
between perceived quality of service and attitudes towards cycling may indicate an underlining association between these issues, though determining if there is a causal connection (i.e. if unsatisfactory experiences with the LBSS leads to individuals developing negative attitudes towards cycling in general) will require additional empirical research with members.
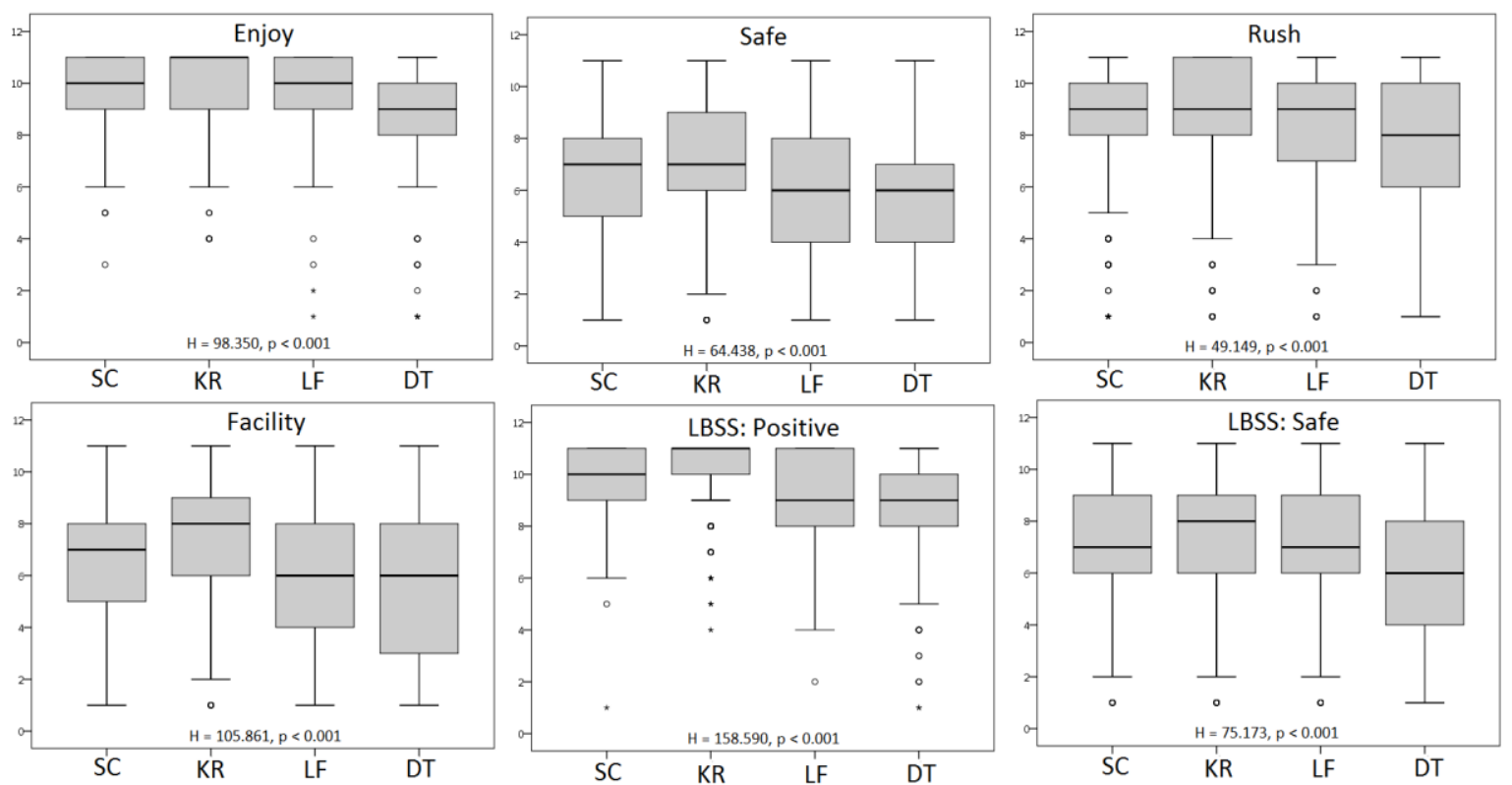

Figure 6: Boxplots of the member segments on attitudes towards cycling and the London Bicycle Sharing Scheme outlined in Table 2

The final group of descriptive variables evaluated in the analysis covers the socioeconomic characteristics of the member segments, with the results of this comparison summarised in Table 4. In this instance, only one significant difference is identified between the segments, concerning member residence. Dissatisfied Out-of-Towners have a higher occurrence of residence in the SouthEast of England. Linking this observation to Dissatisfied Out-of-Towner's higher frequency of using the LBSS for commuting and professional business trips may indicate that this segment contains members that commute into London on an alternative mode of transport (e.g. train or bus) and then make use of the LBSS for the last-mile journey to their place of work as well as work related trips whilst in London. More generally, the low level of inter-segment variation regarding socioeconomic characteristics implies that, for the purpose of quality of service evaluations in bicycle sharing schemes, these characteristics are relatively ineffective at delineating different member groups. 
Table 4: The socioeconomic characteristics of the member segments

\begin{tabular}{|c|c|c|c|c|c|}
\hline Variable & Categorv & SC & KR & LF & DT \\
\hline & & $(n=459)$ & $(\mathrm{n}=484)$ & $(n=320)$ & $(\mathrm{n}=213)$ \\
\hline \multirow{6}{*}{$\begin{array}{l}\text { Age } \\
x^{2}=11.679, p=.703\end{array}$} & $16-24$ & $3.7 \%$ & $3.3 \%$ & $4.0 \%$ & $2.8 \%$ \\
\hline & $25-34$ & $28.0 \%$ & $23.9 \%$ & $33.1 \%$ & $26.6 \%$ \\
\hline & $35-44$ & $29.5 \%$ & $30.7 \%$ & $27.6 \%$ & $30.4 \%$ \\
\hline & $45-54$ & $23.6 \%$ & $27.0 \%$ & $23.5 \%$ & $25.2 \%$ \\
\hline & $55-34$ & $12.9 \%$ & $13.3 \%$ & $10.5 \%$ & $12.6 \%$ \\
\hline & $65+$ & $2.2 \%$ & $1.9 \%$ & $1.2 \%$ & $2.3 \%$ \\
\hline \multirow{2}{*}{$\begin{array}{l}\text { Gender } \\
x^{2}=1.322, p=.724\end{array}$} & Female & $20.4 \%$ & $23.4 \%$ & $21.7 \%$ & $21.5 \%$ \\
\hline & Male & $79.6 \%$ & $76.6 \%$ & $78.3 \%$ & $78.5 \%$ \\
\hline \multirow{7}{*}{$\begin{array}{l}\text { Economic Status } \\
x^{2}=16.892, p=.531\end{array}$} & Employed Full-time & $89.1 \%$ & $85.3 \%$ & $90.1 \%$ & $87.4 \%$ \\
\hline & Employed Part-time & $6.3 \%$ & $6.8 \%$ & $5.0 \%$ & $7.5 \%$ \\
\hline & Looking after Home & $0.0 \%$ & $0.6 \%$ & $0.0 \%$ & $0.0 \%$ \\
\hline & Retired & $1.5 \%$ & $2.9 \%$ & $1.5 \%$ & $1.4 \%$ \\
\hline & Unemployed & $1.1 \%$ & $1.0 \%$ & $1.5 \%$ & $1.4 \%$ \\
\hline & Student & $1.8 \%$ & $2.5 \%$ & $1.2 \%$ & $1.9 \%$ \\
\hline & Other & $0.2 \%$ & $0.8 \%$ & $0.6 \%$ & $0.5 \%$ \\
\hline Household & Less than $f 10,000$ & $3.1 \%$ & $2.9 \%$ & $2.8 \%$ & $1.9 \%$ \\
\hline \multirow{6}{*}{$\begin{array}{l}\text { Income } \\
x^{2}=16.282, p=.573\end{array}$} & $£ 10-14,999$ & $1.1 \%$ & $2.1 \%$ & $0.9 \%$ & $1.9 \%$ \\
\hline & $£ 15-19,999$ & $2.2 \%$ & $2.1 \%$ & $2.5 \%$ & $3.3 \%$ \\
\hline & $£ 20-29,999$ & $8.5 \%$ & $5.2 \%$ & $9.0 \%$ & $5.6 \%$ \\
\hline & $£ 30-39-999$ & $10.3 \%$ & $11.2 \%$ & $12.1 \%$ & $14.0 \%$ \\
\hline & $£ 40-75,000$ & $28.7 \%$ & $30.3 \%$ & $28.8 \%$ & $23.4 \%$ \\
\hline & Over $£ 75,000$ & $46.2 \%$ & $46.3 \%$ & $44.0 \%$ & $50.0 \%$ \\
\hline \multirow{5}{*}{$\begin{array}{l}\text { Ethnicity } \\
x^{2}=24.293, p=.019\end{array}$} & White & $91.5 \%$ & $91.7 \%$ & $93.2 \%$ & $95.3 \%$ \\
\hline & Mixed & $4.4 \%$ & $2.7 \%$ & $1.5 \%$ & $0.9 \%$ \\
\hline & Asian & $1.5 \%$ & $3.3 \%$ & $2.8 \%$ & $0.0 \%$ \\
\hline & Black & $0.9 \%$ & $0.4 \%$ & $0.9 \%$ & $0.0 \%$ \\
\hline & Other & $1.8 \%$ & $1.9 \%$ & $1.5 \%$ & $3.7 \%$ \\
\hline \multirow{3}{*}{$\begin{array}{l}\text { Residence } \\
x^{2}=22.052, p<.001\end{array}$} & Rest of UK & $9.0 \%$ & $10.0 \%$ & $4.0 \%$ & $9.3 \%$ \\
\hline & South East England & $17.5 \%$ & $21.8 \%$ & $16.4 \%$ & $25.7 \%$ \\
\hline & London & $73.5 \%$ & $68.3 \%$ & $79.6 \%$ & $65.0 \%$ \\
\hline
\end{tabular}

\section{Conclusions}

The rapid diffusion of bicycle sharing schemes in urban areas is leading to the establishment of a new market for public transport services. Operators and local authorities tasked with managing these schemes face two important questions covering how to attract new members and how to retain existing members. The market appraisal of existing members of the LBSS presented in this paper provides insights to these questions by considering the consumer structure of this emerging market in reference to issues that are inherent in consumer experience such as perceived quality of service. Through this appraisal, insights can be generated concerning what types of users are attracted to such schemes in large urban environments and, though an appreciation of the characteristics of these user 
groups, how policy can be attuned to their needs and expectations. To this end, the results of the analysis offer the following contributions for both academic knowledge and policy development.

First, the findings of this paper enrichen the understanding of consumer experience with bicycle sharing schemes. Initial examinations in this area have approached the topic at the market level in an attempt to identify issues that tend to hold true for all users (Zhang et al. 2015; Manzi and Saibene, 2017). Such an approach can be effective in the development of general strategy which may be of use when setting up the operation of a new scheme. However, general strategy can be quite restrictive when managing an existing scheme that has a wide user base. The market segmentation analysis presented here provides a more nuanced perspective on this issue by demonstrating that bicycle sharing schemes can attract different groups of users that are distinct in terms of their experiences with the scheme, the manner in which they use the scheme, and their behavioural intentions towards the scheme. Through an appreciation of the similarities and differences between scheme users, the development of sub-market strategy, which responds to the particular features of the targeted market segment, can be considered.

To provide an idea of how sub-market strategies could be developed out of the market intelligence derived from the segmentation analysis, consider the following proposals. Low Frequenters appear to be more price sensitive, with relatively negative perceptions concerning the value for money of the scheme. Targeting this segment with a pricing structure that reduces costs of access (e.g. with discounts or pricing levels differentiated around the usage patterns of this segment) could be a means through which to improve the perceived satisfaction amongst this member group. Keen Renewers tend to have the highest level of satisfaction with the scheme and express a high willingness to recommend the scheme. Targeting this segment with an incentive to indorse the scheme with their friends and family (e.g. through gift vouchers to both parties) could represent a strategy to increase overall scheme membership. A more involved strategy could be to conduct follow-up analysis with a particular segment of members to attain additional information regarding their experiences and desires. For instance, Dissatisfied Out-of-Towners could be asked to participate in focus groups to ascertain the particular sequences of issues underpinning their relative dissatisfaction with the scheme and their opinions regarding what aspects need to be improved. As such, public transport operators can combine market segmentation analysis with other methods of investigation to produce a richer understanding of how their customers perceive the service and what modifications can be enacted to enhance their satisfaction with it.

At a more general level, local transport authorities and service providers often gather a large quantity of data concerning their operations either passively (e.g. through ticketing information) or actively (e.g. through passenger surveys). The segmentation analysis presented here demonstrates the additional value that can be extracted from existing operations data (i.e. the LBSS members survey) to generate an improved understanding of the experiences and expectations that customers have towards a service. One particular strength of conducting secondary data analysis using such sources is that the research is targeted on the specific issues that authorities and operators consider to be important. With this in mind, researchers examining such datasets can be confident that the analysis they conduct is of direct policy relevance, and should ensure that the research can be easily understood and incorporated into strategy. Moreover, as shared mobility services expand, it may become important to consider what quality of service dimensions transfer between the alternative service forms (e.g. bicycle, car, and lift sharing) and what dimensions are unique. Understanding the degree to which conventional quality of service dimensions (e.g. the responsiveness of service personal) are applicable in the emerging market for shared mobility services is likely to be of value in 
determining the appropriateness of the existing quality of service measurements in this area. These could represent fertile topics for future research to consider.

\section{References}

Athanassopoulos, A. D. (2000). Customer Satisfaction Cues To Support Market Segmentation and Explain Switching Behavior. Journal of Business Research, 47(3), 191-207.

https://doi.org/10.1016/S0148-2963(98)00060-5

Banister, D. (2005). Unsustainable Transport: City Transport in the New Century: The Transport Crisis. London; New York: Routledge.

Beecham, R., \& Wood, J. (2014). Exploring gendered cycling behaviours within a large-scale behavioural data-set. Transportation Planning and Technology, 37(1), 83-97.

https://doi.org/10.1080/03081060.2013.844903

Berry, L. L., Zeithaml, V. A., \& Parasuraman, A. (1985). Quality counts in services, too. Business Horizons, 28(3), 44-52. https://doi.org/10.1016/0007-6813(85)90008-4

Caliński, T., \& Harabasz, J. (1974). A dendrite method for cluster analysis. Communications in Statistics, 3(1), 1-27. https://doi.org/10.1080/03610927408827101

Caulfield, B., O'Mahony, M., Brazil, W., \& Weldon, P. (2017). Examining usage patterns of a bikesharing scheme in a medium sized city. Transportation Research Part A: Policy and Practice, 100, 152-161. https://doi.org/10.1016/j.tra.2017.04.023

Médard de Chardon, C., Caruso, G., \& Thomas, I. (2017). Bicycle sharing system "success" determinants. Transportation Research Part A: Policy and Practice, 100, 202-214. https://doi.org/10.1016/j.tra.2017.04.020

Chou, P.-F., Lu, C.-S., \& Chang, Y.-H. (2014). Effects of service quality and customer satisfaction on customer loyalty in high-speed rail services in Taiwan. Transportmetrica A: Transport Science, 10(10), 917-945. https://doi.org/10.1080/23249935.2014.915247

Cronin, J. J., \& Taylor, S. A. (1992). Measuring Service Quality: A Reexamination and Extension. Journal of Marketing, 56(3), 55-68. https://doi.org/10.2307/1252296

Cronin, J. J., \& Taylor, S. A. (1994). SERVPERF versus SERVQUAL: Reconciling Performance-Based and Perceptions-Minus-Expectations Measurement of Service Quality. Journal of Marketing, 58(1), 125131. https://doi.org/10.2307/1252256

Cronin, J. J., Brady, M. K., \& Hult, G. T. M. (2000). Assessing the effects of quality, value, and customer satisfaction on consumer behavioral intentions in service environments. Journal of Retailing, 76(2), 193-218. https://doi.org/10.1016/S0022-4359(00)00028-2

Damant-Sirois, G., Grimsrud, M., \& El-Geneidy, A. M. (2014). What's your type: a multidimensional cyclist typology. Transportation, 41(6), 1153-1169. https://doi.org/10.1007/s11116-014-9523-8 
Damant-Sirois, G., \& El-Geneidy, A. M. (2015). Who cycles more? Determining cycling frequency through a segmentation approach in Montreal, Canada. Transportation Research Part A: Policy and Practice, 77, 113-125. https://doi.org/10.1016/i.tra.2015.03.028

Dill, J., \& McNeil, N. (2013). Four Types of Cyclists? Examination of Typology for Better Understanding of Bicycling Behavior and Potential. Transportation Research Record: Journal of the Transportation Research Board, 2387, 129-138. https://doi.org/10.3141/2387-15

Eboli, L., \& Mazzulla, G. (2007). Service Quality Attributes Affecting Customer Satisfaction for Bus Transit. Journal of Public Transportation, 10(3). https://doi.org/http://dx.doi.org/10.5038/2375$\underline{0901.10 .3 .2}$

Eboli, L., \& Mazzulla, G. (2015). Relationships between rail passengers' satisfaction and service quality: a framework for identifying key service factors. Public Transport, 7(2), 185-201. https://doi.org/10.1007/s12469-014-0096-x

Everitt, B. S., Landau, D. S., \& Leese, D. M. (2009). Cluster Analysis. John Wiley \& Sons.

Fick, G. R., \& Ritchie, J. R. B. (1991). Measuring Service Quality in the Travel and Tourism Industry. Journal of Travel Research, 30(2), 2-9. https://doi.org/10.1177/004728759103000201

Fishman, E., Washington, S., \& Haworth, N. (2013). Bike Share: A Synthesis of the Literature. Transport Reviews, 33(2), 148-165. https://doi.org/10.1080/01441647.2013.775612

Fishman, E., Washington, S., Haworth, N., \& Watson, A. (2015). Factors influencing bike share membership: An analysis of Melbourne and Brisbane. Transportation Research Part A: Policy and Practice, 71, 17-30. https://doi.org/10.1016/j.tra.2014.10.021

Goldman, T., \& Gorham, R. (2006). Sustainable urban transport: Four innovative directions. Technology in Society, 28(1-2), 261-273. https://doi.org/10.1016/i.techsoc.2005.10.007

Goodman, A., Green, J., \& Woodcock, J. (2014). The role of bicycle sharing systems in normalising the image of cycling: An observational study of London cyclists. Journal of Transport \& Health, 1(1), 5-8. https://doi.org/10.1016/j.jth.2013.07.001

Grisé, E., \& El-Geneidy, A. (2017). Evaluating the relationship between socially (dis)advantaged neighbourhoods and customer satisfaction of bus service in London, U.K. Journal of Transport Geography, 58, 166-175. https://doi.org/10.1016/i.jtrangeo.2016.11.016

Hartigan, J. A., \& Wong, M. A. (1979). Algorithm AS 136: A K-Means Clustering Algorithm. Applied Statistics, 28(1), 100. https://doi.org/10.2307/2346830

Kim, J., Choi, K., Kim, S., \& Fujii, S. (2017). How to promote sustainable public bike system from a psychological perspective? International Journal of Sustainable Transportation, 11(4), 272-281. https://doi.org/10.1080/15568318.2016.1252450 
Lathia, N., Ahmed, S., \& Capra, L. (2012). Measuring the impact of opening the London shared bicycle scheme to casual users. Transportation Research Part C: Emerging Technologies, 22, 88-102. https://doi.org/10.1016/i.trc.2011.12.004

Lierop, D. van, Badami, M. G., \& El-Geneidy, A. M. (2017). What influences satisfaction and loyalty in public transport? A review of the literature. Transport Reviews, 0(0), 1-21.

https://doi.org/10.1080/01441647.2017.1298683

Lin, C. (2002). Segmenting customer brand preference: demographic or psychographic. Journal of Product \& Brand Management, 11(4), 249-268. https://doi.org/10.1108/10610420210435443

Mahmoud, M., \& Hine, J. (2016). Measuring the influence of bus service quality on the perception of users. Transportation Planning and Technology, 0(0), 1-16.

https://doi.org/10.1080/03081060.2016.1142224

Manzi, D. G., \& Saibene, M. G. (2017). Are they telling the truth? Revealing hidden traits of satisfaction with a public bike sharing service. International Journal of Sustainable Transportation, 0(ja), 0-0. https://doi.org/10.1080/15568318.2017.1353186

Médard de Chardon, C., Caruso, G., \& Thomas, I. (2017). Bicycle sharing system "success" determinants. Transportation Research Part A: Policy and Practice, 100, 202-214.

https://doi.org/10.1016/j.tra.2017.04.020

Mooi, E., \& Sarstedt, M. (2011). A Concise Guide to Market Research: The Process, Data, and Methods Using IBM SPSS Statistics. Springer.

Morton, C., Caulfield, B., \& Anable, J. (2016). Customer perceptions of quality of service in public transport: Evidence for bus transit in Scotland. Case Studies on Transport Policy, 4(3), 199-207. https://doi.org/10.1016/j.cstp.2016.03.002

Nathanail, E. (2008). Measuring the quality of service for passengers on the hellenic railways. Transportation Research Part A: Policy and Practice, 42(1), 48-66.

https://doi.org/10.1016/i.tra.2007.06.006

Nikitas, A., Wallgren, P., \& Rexfelt, O. (2015). The paradox of public acceptance of bike sharing in Gothenburg. Proceedings of the Institution of Civil Engineers - Engineering Sustainability, 169(3), 101-113. https://doi.org/10.1680/jensu.14.00070

Ogilvie, F., \& Goodman, A. (2012). Inequalities in usage of a public bicycle sharing scheme: Sociodemographic predictors of uptake and usage of the London (UK) cycle hire scheme. Preventive Medicine, 55(1), 40-45. https://doi.org/10.1016/i.ypmed.2012.05.002

Ostrowski, P. L., O'Brien, T. V., \& Gordon, G. L. (1993). Service Quality and Customer Loyalty in the Commercial Airline Industry. Journal of Travel Research, 32(2), 16-24.

https://doi.org/10.1177/004728759303200203 
de Oña, R., \& de Oña, J. (2013). Analyzing transit service quality evolution using decision trees and gender segmentation. WIT Transactions on The Built Environment, 130, 611-621.

https://doi.org/10.2495/UT130491

de Oña, R., López, G., Rios, F. J. D. de los, \& de Oña, J. (2014). Cluster Analysis for Diminishing Heterogeneous Opinions of Service Quality Public Transport Passengers. Procedia - Social and Behavioral Sciences, 162, 459-466. https://doi.org/10.1016/j.sbspro.2014.12.227

Pakdil, F., \& Aydın, Ö. (2007). Expectations and perceptions in airline services: An analysis using weighted SERVQUAL scores. Journal of Air Transport Management, 13(4), 229-237. https://doi.org/10.1016/i.jairtraman.2007.04.001

Parkes, S. D., Marsden, G., Shaheen, S. A., \& Cohen, A. P. (2013). Understanding the diffusion of public bikesharing systems: evidence from Europe and North America. Journal of Transport Geography, 31, 94-103. https://doi.org/10.1016/i.jtrangeo.2013.06.003

Parasuraman, A., Zeithaml, V. A., \& Berry, L. L. (1985). A Conceptual Model of Service Quality and Its Implications for Future Research. Journal of Marketing, 49(4), 41-50.

https://doi.org/10.2307/1251430

Parasuraman, A., Zeithaml, V. A., \& Berry, L. L. (1988). SERVQUAL: A multiple-item scale for measuring consumer perceptions of service quality. Journal of Retailing, 64(1), 12-40.

Parasuraman, A., Berry, L. L., \& Zeithaml, V. A. (1991). Refinement and reassessment of the SERVQUAL scale. Journal of Retailing, 67(4), 420-450.

Ricci, M. (2015). Bike sharing: A review of evidence on impacts and processes of implementation and operation. Research in Transportation Business \& Management, 15, 28-38.

https://doi.org/10.1016/j.rtbm.2015.03.003

Savan, B., Cohlmeyer, E., \& Ledsham, T. (2017). Integrated strategies to accelerate the adoption of cycling for transportation. Transportation Research Part F: Traffic Psychology and Behaviour, 46, Part A, 236-249. https://doi.org/10.1016/i.trf.2017.03.002

Shaheen, S., Guzman, S., \& Zhang, H. (2010). Bikesharing in Europe, the Americas, and Asia: Past, Present, and Future. Transportation Research Record: Journal of the Transportation Research Board, 2143, 159-167. https://doi.org/10.3141/2143-20

Shaheen, S., Zhang, H., Martin, E., \& Guzman, S. (2011). China's Hangzhou Public Bicycle: Understanding Early Adoption and Behavioral Response to Bikesharing. Transportation Research Record: Journal of the Transportation Research Board, 2247, 33-41. https://doi.org/10.3141/2247$\underline{05}$

Smith, W. R. (1956). Product Differentiation and Market Segmentation as Alternative Marketing Strategies. The Journal of Marketing, 21(1), 3-8. Retrieved from http://www.jstor.org/stable/1247695 
Stradling, S., Carreno, M., Rye, T., \& Noble, A. (2007). Passenger perceptions and the ideal urban bus journey experience. Transport Policy, 14(4), 283-292. https://doi.org/10.1016/j.tranpol.2007.02.003

Sánchez-Pérez, M., Abad, J. C. G., Carrillo, G. M. M., \& Fernández, R. S. (2007). Effects of service quality dimensions on behavioural purchase intentions: A study in public-sector transport. Managing Service Quality: An International Journal, 17(2), 134-151.

https://doi.org/10.1108/09604520710735164

Taylor, S. A., \& Baker, T. L. (1994). An assessment of the relationship between service quality and customer satisfaction in the formation of consumers' purchase intentions. Journal of Retailing, 70(2), 163-178. https://doi.org/10.1016/0022-4359(94)90013-2

Transport for London, (2015). Annual report and statement of accounts 2014/15. Available at: http://content.tfl.gov.uk/annual-report-2014-15.pdf, Accessed: 15/08/2017.

Transport for London (2016a). Santander Cycles Performance Report. Available at: http://content.tfl.gov.uk/santander-cycles-transparency-to-end-of-september-2016.pdf, Accessed: $27 / 03 / 2017$

Transport for London (2016b). Santander Cycles Customer Satisfaction and Usage Survey: Members only wave 11. Available at: http://content.tfl.gov.uk/santander-cycles-members.pdf, Accessed: $28 / 03 / 2017$

Webb, D. (1998). Segmenting Police "Customers" on the Basis of their Service Quality Expectations. The Service Industries Journal, 18(1), 72-100.

https://doi.org/10.1080/02642069800000005

Webster, C. (1989). Can Consumers be Segmented on the Basis of their Service Quality Expectations? Journal of Services Marketing, 3(2), 35-53.

https://doi.org/10.1108/EUM0000000002485

Yanik, S., Aktas, E., \& Topcu, I. (2017). Traveler Satisfaction in Rapid Rail Systems: The Case of Istanbul Metro. International Journal of Sustainable Transportation, 0 (ja), 00-00. https://doi.org/10.1080/15568318.2017.1301602

Yaya, L. H. P., Fortià, M. F., Canals, C. S., \& Marimon, F. (2014). Service quality assessment of public transport and the implication role of demographic characteristics. Public Transport, 1-20. https://doi.org/10.1007/s12469-014-0099-7

Zhang, D., Xu, X., \& Yang, X. (2015). User Satisfaction and Its Impacts on the Use of a Public Bicycle System: Empirical Studies from Hangzhou, China. Transportation Research Record: Journal of the Transportation Research Board, 2512, 56-65. https://doi.org/10.3141/2512-07 